ECCOMAS

\section{Proceedia}

COMPDYN 2021

$8^{\text {th }}$ ECCOMAS Thematic Conference on Computational Methods in Structural Dynamics and Earthquake Engineering

M. Papadrakakis, M. Fragiadakis (eds.) Streamed from Athens, Greece, 28 - 30 June 2021

\title{
AN INNOVATIVE STEEL DAMPER WITH ADAPTIVE HYSTERETIC BEHAVIOR
}

\author{
Emanuele Gandelli ${ }^{1}$, Johan Distl ${ }^{1}$, Peter Huber ${ }^{1}$, Christian Braun ${ }^{1}$ \\ ${ }^{1}$ Maurer Engineering GmbH, R\&D department \\ Frankfurter Ring 193, 80807, München, Germany \\ \{e.gandelli, j.distl, p.huber, c.braun\}@maurer.eu
}

\begin{abstract}
An ideal antiseismic technology should perform at high efficiency independently from the intensity of the ground shaking. However, traditional bilinear hysteretic dampers (BHDs) are commonly designed for severe ultimate limit state earthquakes resulting in a poor efficiency during weak but frequent events since they are engaged in their elastic region offering negligible damping. This can cause high peak floor accelerations (PFAs) that are detrimental for sensitive non-structural components, like elevators, and electric networks, whose integrity is essential for a prompt operation of the building after the quake. This shortcoming can be improved through a second generation of hysteretic dampers capable to produce different yielding levels based on the intensity of the occurring earthquake. Within this framework, the innovative Adaptive Hysteretic Damper (AHD) is presented in this paper. The results of forcedisplacement tests carried out on a 2.0MN prototype are argued and prove its robustness and reliability under several repeated cyclic motions. A simple design approach for braced frames implementing the AHDs is eventually proposed and applied to a real case-study building to quantify, through NLTH analyses, the enhanced seismic performances offered by this technology compared to traditional BHDs.
\end{abstract}

Keywords: Steel Dampers, Adaptive Hysteretic Behavior, Serviceability Limit State, Ultimate Limit State, Non-structural Component. 


\section{INTRODUCTION}

Among most advanced antiseismic design guidelines, the Eurocode 8 [1], embracing Performance Based Design (PBD) procedures [2], establishes two different seismic scenarios and relevant performance requirements:

- the most severe "Ultimate Limit State" (ULS) scenario features 10\% of exceedance probability over the reference period $V_{R}=50$ years (i.e. return period $T_{R}=475$ years). Under ULS seismic events, the structure shall be capable to withstand the seismic loads without any global or local collapse preserving as well a residual lateral strength after the quake ("structural safety requirement" or "no-collapse requirement");

- the less intense (but more frequent) "Serviceability Limit State" (SLS) scenario provides $10 \%$ of exceedance probability over the reference period $V_{R}=10 y e a r s$ (i.e. return period $\mathrm{T}_{\mathrm{R}}=95$ years). Under SLS seismic events, the structure, besides not suffering any structural damage, shall remain fully operational ("damage limitation requirement").

In order to meet the second requirement, "acceleration sensitive", "drift-sensitive", and "displacement sensitive" non-structural components (NSCs) should be protected against detrimental high peak floor accelerations (PFAs), interstorey-drifts $(\Delta)$, and absolute displacements (D) [3-5]. A list of most common NSCs grouped into these categories is given in Table 1. It is worth noting that the integrity of "drift-sensitive" NSCs should not represent a challenging target for structural engineers since usually enveloped, in average terms, by narrower or comparable SLS lateral deflection limits for structural elements. For instance, among weakest NSCs [3-6], curtain and infill walls, are characterized by a higher strength $\left(\Delta_{\text {lim }}\right)$ compared to more critical reinforced concrete columns $\left(\Delta_{\text {lim }}=0.75 \%\right.$ vs. $\left.\Delta_{\text {lim }}=0.66 \%\right)$ [7]. Since characterized by several different layouts, the definition of the damage thresholds for "displacement-sensitive" NSCs often needs the "expert judgment". However, the fulfillment of these checks can be easily ensured through conventional design approaches that usually aim to control the storeys' lateral displacements [5]. On the contrary, the assessment of the integrity of "acceleration-sensitive" NSCs is more questionable since based on more complex "floor response spectrum" analyses that require the (rarely available) knowledge of the natural frequency and inherent damping of each NSC $[8,9]$. Antiseismic technologies capable to minimize the spectral accelerations over a wide range of NSCs' oscillation periods represent therefore the best option.

\begin{tabular}{lll}
\hline & nonstructural components' categories \\
\hline acc. sensitive & drift sensitive & disp. sensitive \\
\hline false ceilings & infill walls & parapets \\
elevators & glass windows and doors & storage racks \\
UPS battery cabinets & pipelines & chimneys \\
UPS switchboard panels & & thermal/seismic joints \\
UPS distribution panels & & \\
\hline
\end{tabular}

Table 1: Most common "acceleration-sensitive", "drift-sensitive", and "displacement-sensitive" NSCs [3-5].

Among modern antiseismic technologies, Hysteretic Dampers (HDs), firstly introduced in the '70s of the last century [10], are typically installed in braced frames in order to dissipate the seismic energy through the plastic deformation of sacrificial mild steel components. Their force-displacement (F-d) response is not (or only scarcely) affected by velocity and is conventionally modelled by means of bilinear hysteretic models. Over the last thirty years, HDs ex- 
ploiting axial loads, shear loads, bending, and torsion have been developed [11] and worldwide applied for the seismic protection of schools and hospitals [12, 13].

Despite the lower costs compared to other technologies (e.g. fluid viscous dampers), the use of HDs not always represents the best option for the protection of high-technological or strategic buildings [5]. Indeed, a recent experimental study [14] has shown that, on one hand, the introduction of the hysteretic braces allows a significant reduction of the frame lateral deformation, on the other hand, can trigger a huge increase (up to 300\%) of PFAs. Enhancements in antiseismic technologies and new approaches based on low-damage methodologies are hence needed $[15,16]$. Nevertheless, common methods for the design of new structures, as well as for the retrofit of existing ones, account the "structural safety requirement" at the ULS only [17-19]. In order to improve this unacceptable situation, the innovative Adaptive Hysteretic Damper (AHD), a device capable to modulate its effective damping and stiffness based on the intensity of the occurring earthquake, is presented in this paper. The reliability and robustness of the AHD under multiple excitations, is proven through experimental tests carried out on a full-scale $2.0 \mathrm{MN}$ prototype. Linear equivalent mechanical parameters to be exploited in simple response spectrum analyses for the design of braced frames implementing the AHDs are argued hereafter and exemplified through a case-study building. The comparison with the response calculated for the same building protected by conventional bilinear hysteretic dampers allows to claim the following achievements: (a) not impaired structural performance under severe ULS earthquakes; (b) enhanced protection of "accelerationsensitive" NSCs under weak but frequent SLS events.

\section{WORKING PRINCIPLE OF THE NEW DAMPER}

Among common steel dampers, the Shear Hysteretic Panel (SHP) was the starting point for the development of the novel Adaptive Hysteretic Damper (AHD). The SHP consists of a steel plate with equally spaced openings delimiting a set of dissipative laminae (Fig. 1-left) [20]. The relative motion between the bottom and the upper edge of the SHP induces the shear deformation of the laminae first in the elastic and later in the plastic range (Fig.1-center) resulting in a typical bilinear hysteretic response (Fig.1-right). Despite SHPs exhibit a considerable energy absorption capacity and lateral stiffness even under small drift angles $\left(\gamma_{L}=d / L\right)$, that makes them very suitable for braced frames, their widespread application has been so far constrained by their unsatisfactory strength against out of plane loads (buckling).
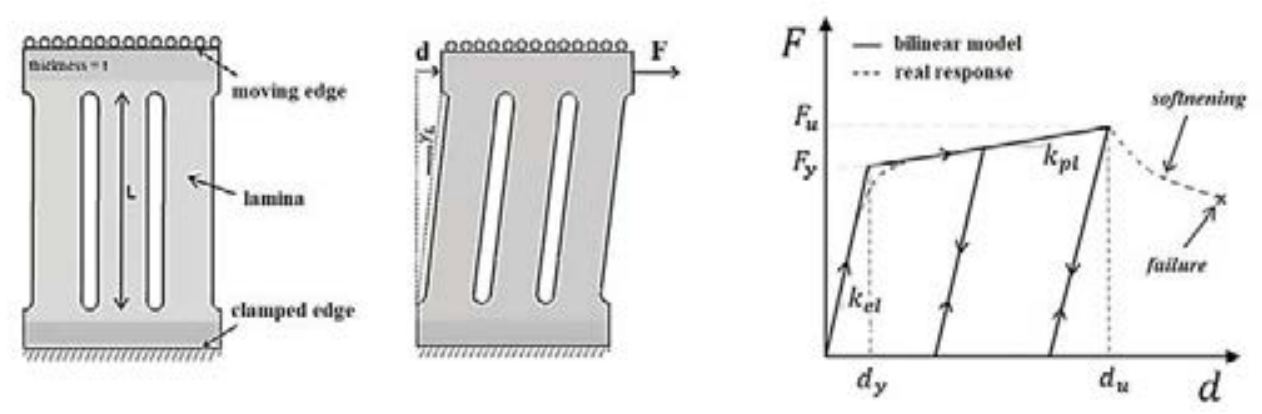

Figure 1: SHP damper: undeformed configuration (left), deformed configuration (centre), and typical bilinear Fd response (right).

The main novelties introduced by the AHD are shown in Fig. 2:

- the three-dimensional "hollow-section" arrangement of multiple laminae with an optimized "hourglass-shape" to form a dissipative core (the orange color element in Fig. 2- 
left) capable to withstand high drift angles (hence displacement amplitudes) and overcome buckling problems. The clockwise alternated transmission of tension and compression loads at the corners of the core engages the shear deformation of the laminae;

- the "in series connection" between a minor (D1, green element) and a major (D2, orange element) dissipative core (Fig. 2-left) allows the development of an innovative "two-stages" hysteretic behavior (Fig. 2-right). The different yielding strengths of the minor $\left(F_{y, D 1}\right)$ and major $\left(F_{y, D 2}>F_{y, D 1}\right)$ hysteretic cores are obtained by varying the number and/or the geometry of the hysteretic laminae. Two connection plates (CP) are used to link the dissipative cores to the main structural frame while a plate featuring a slotted hole, hereafter referred as "GAP-element", is introduced to mutually link the two dissipative cores. This connector acts as a very stiff end-stroke stopper that: (a) during minor SLS earthquakes, allows the exclusive plastic engagement of the minor core; (b) during severe ULS events, enforces the activation of the major dissipative core to achieve higher levels of effective stiffness and equivalent damping.
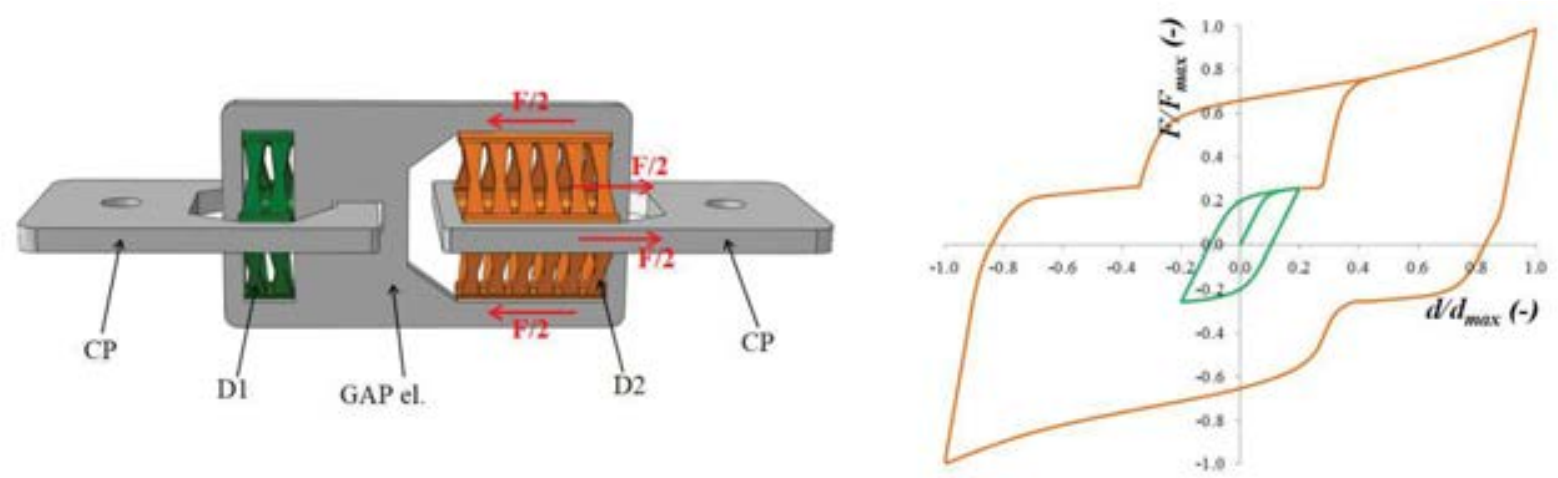

Figure 2: Adaptive Hysteretic Damper: device assembly (left) and innovative "two-stages" hysteretic loop (right).

Assuming that both the $\mathrm{CP}$ and the GAP elements offer very stiff elastic reactions $\left(k_{e l} \rightarrow\right.$ $+\infty$ ) even during the most severe design loads, the F-d backbone curve of the AHD (Fig. 3left) can be described through an analytical model that depend on the following parameters only: (a) yielding force of the minor $\left(F_{y, D 1}\right)$ and major $\left(F_{y, D 2}\right)$ core; (b) elastic stiffness of the minor $\left(k_{e l, D 1}\right)$ and major $\left(k_{e l, D 2}>k_{e l, D 1}\right)$ core; (c) plastic stiffness of the minor $\left(k_{p l, D 1}\right)$ and major $\left(k_{p l, D 2}>k_{p l, D 1}\right)$ core; (d) width of the slotted hole of the gap-connector $\left(d_{G}\right)$. Four different displacement fields can be distinguished:

- $\underline{\text { field A }}\left(d_{\max } \leq d_{y, 1}\right)$ : both D1 and D2 operate in their elastic regime ( $d_{y, 1}$ denotes the yielding displacement of the minor core). The device reacts as a soft spring to SLS static and dynamic loads;

- field B $\left(d_{y, 1}<d_{\max } \leq d_{E S}\right)$ : D1 is deformed in its plastic field while D2 still reacts in the elastic region $\left(\mathrm{d}_{\mathrm{ES}}>\mathrm{d}_{\mathrm{G}}\right.$ represents the displacement amplitude at the attainment of the contact in the gap-connector element). The device offers a minor effective stiffness and a certain damping level in order to minimize the effects of frequent SLS earthquakes;

- field C $\left(d_{E S}<d_{\max } \leq d_{y, 2}\right)$ : the attained "contact condition" in the gap-element prevents any further deformation of D1 while, on the contrary, entrusts the incremental loads to D2 that is still reacting in its elastic regime $\left(d_{y, 2}\right.$ denotes the yielding displacement of the minor core); 
- field D $\left(d_{y, 2}<d_{\max } \leq d_{u}\right)$ : the gap-element is still effective and D2 is eventually deformed in its plastic field maximizing the energy dissipation capacity of the damper and providing a higher effective stiffness in order to minimize the structural damages under strong ULS earthquakes.

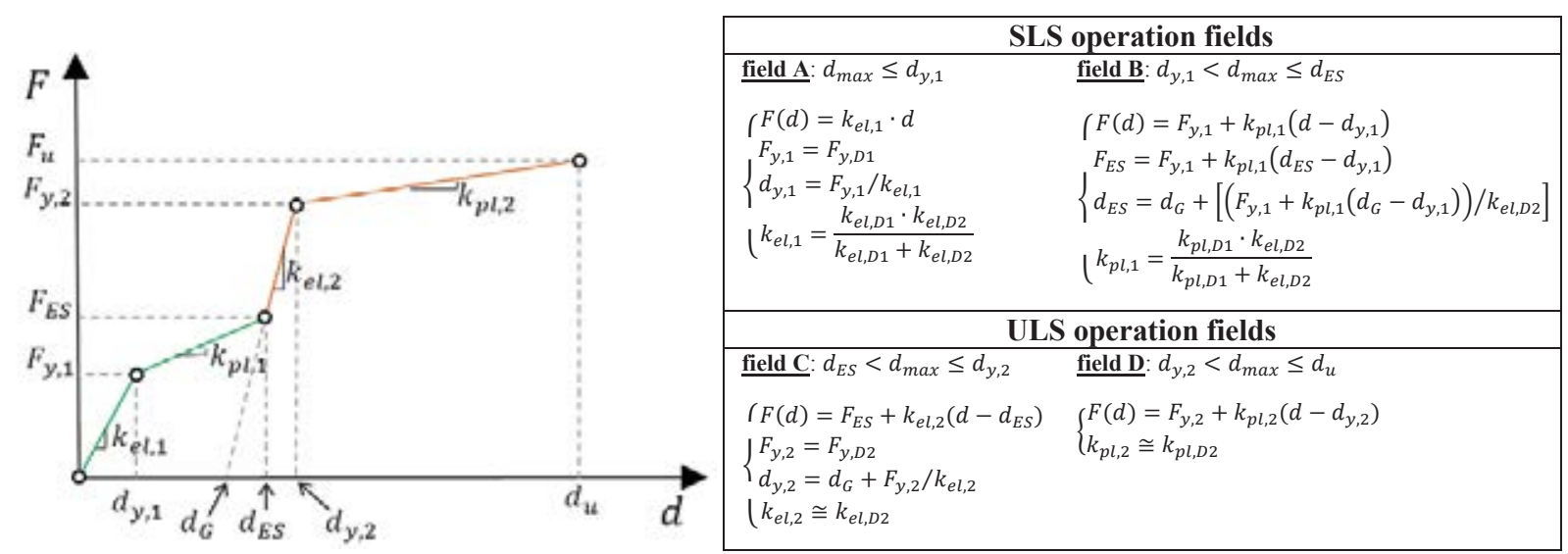

Figure 3: Force-displacement response of the AHD: backbone trend (left) and relevant analytical model (right).

\section{EXPERIMENTAL TESTS}

The force-displacement response of the AHD was assessed in displacement-controlled tests carried out at the Eucentre Lab. (Pavia, Italy) [21] on a full-scale prototype made of structural steel S355 and characterized by: (1) minor hysteretic core featuring $F_{y, D 1}=450 \mathrm{kN}, k_{e l, D 1}=$ $80 \mathrm{kN} / \mathrm{mm}, k_{p l, D 1}=6.0 \mathrm{kN} / \mathrm{mm}$ (2) width of the hole in the gap-connector $d_{G}= \pm 15 \mathrm{~mm}$; (3) major hysteretic core featuring $F_{y, D 2}=1350 \mathrm{kN}, k_{e l, D 2}=240 \mathrm{kN} / \mathrm{mm}, k_{p l, D 2}=$ $18.0 \mathrm{kN} / \mathrm{mm}$.

According to the European Standard EN15129 (§ 6.2) [22], the testing protocol (Table 2) provided four runs with increasing displacement amplitudes equal to $25 \%, 50 \%, 100 \%$, and $132 \%$ of the ULS design displacement $\left(d_{b d}\right)$, respectively. In particular, the first two runs provides "only" 5 cycles and are conceived to assess the response the device for low and medium intensity earthquakes, while the third run ( 10 cycles at $100 \%$ of $\left.d_{b d}\right)$ is exploited to assess the degradation of the offered effective stiffness and damping due to low-cycle fatigue under severe ULS earthquakes. Eventually, in the last run, usually known as "displacementcapacity" test, the robustness of the damper is verified at the overload displacement $d_{c d}$ obtained amplifying $d_{b d}$ by a reliability $\left(\gamma_{x}=1.1\right)$ and a safety $\left(\gamma_{b}=1.2\right)$ factor [1].

\begin{tabular}{llllll}
\hline run & $\begin{array}{l}\text { ampl. } \\
(\mathbf{m m})\end{array}$ & $\begin{array}{l}\text { vel. } \\
(\mathbf{m m} / \mathbf{s})\end{array}$ & shape & cycles & notes \\
\hline 1 & \pm 16.3 & 10 & triangular & 5 & $=0.25 \cdot d_{b d}$ \\
2 & \pm 32.5 & 10 & triangular & 5 & $=0.50 \cdot d_{b d}$ \\
3 & \pm 65.0 & 10 & triangular & 10 & $=1.00 \cdot d_{b d}$ \\
4 & \pm 86.0 & 10 & triangular & 1 & $=1.32 \cdot d_{b d}$ \\
\hline
\end{tabular}

Table 2: Testing protocol.

During the tests, the deformations of the AHD were recorded through an electronic displacement transducer (LVDT) while instantaneous values of axial load by means of the load 
cell of the testing machine. In this regard, Fig. 4 depicts the device in its maximum compression and elongation configurations (achieved during the "displacement-capacity" test) and Fig. 5 shows the recorded experimental loops (overlapped with the analytical backbone curve). The following results can be appreciated:

- a stable response of the AHD during runs No. 1-3. In particular, since the recorded loops of each run are practically overlapped, in agreement with the requirement of the EN 15129, both the energy dissipated per cycle $(E D C)$ and the effective stiffness $\left(k_{e f f}\right)$ of the device did not degrade more than $10 \%$ due to the low-cycle fatigue;

- the absence of sudden stiffness-drops at max/min displacement amplitudes of run no. 4 witnessing the capability of the device to withstand even higher loads/deformations;

- a fair agreement between the analytical F-d backbone plot (red-dashed lines obtained through the Equations in the panel of Fig. 3) and the experimental data.
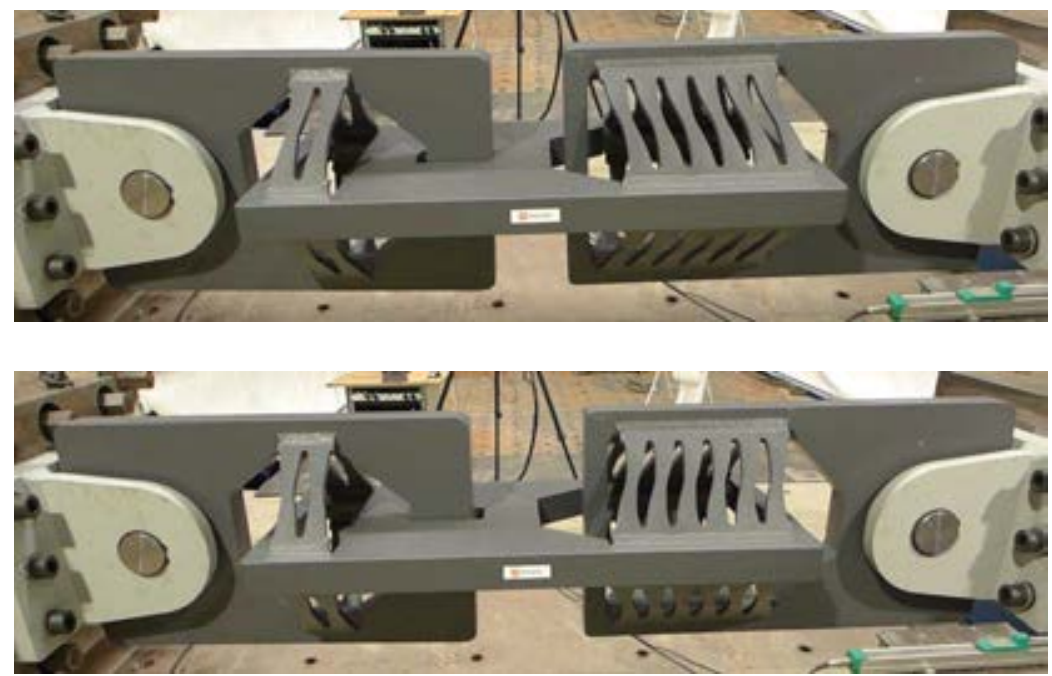

Figure 4: Maximum compression (top) and elongation (bottom) configurations reached by the AHD during run4.
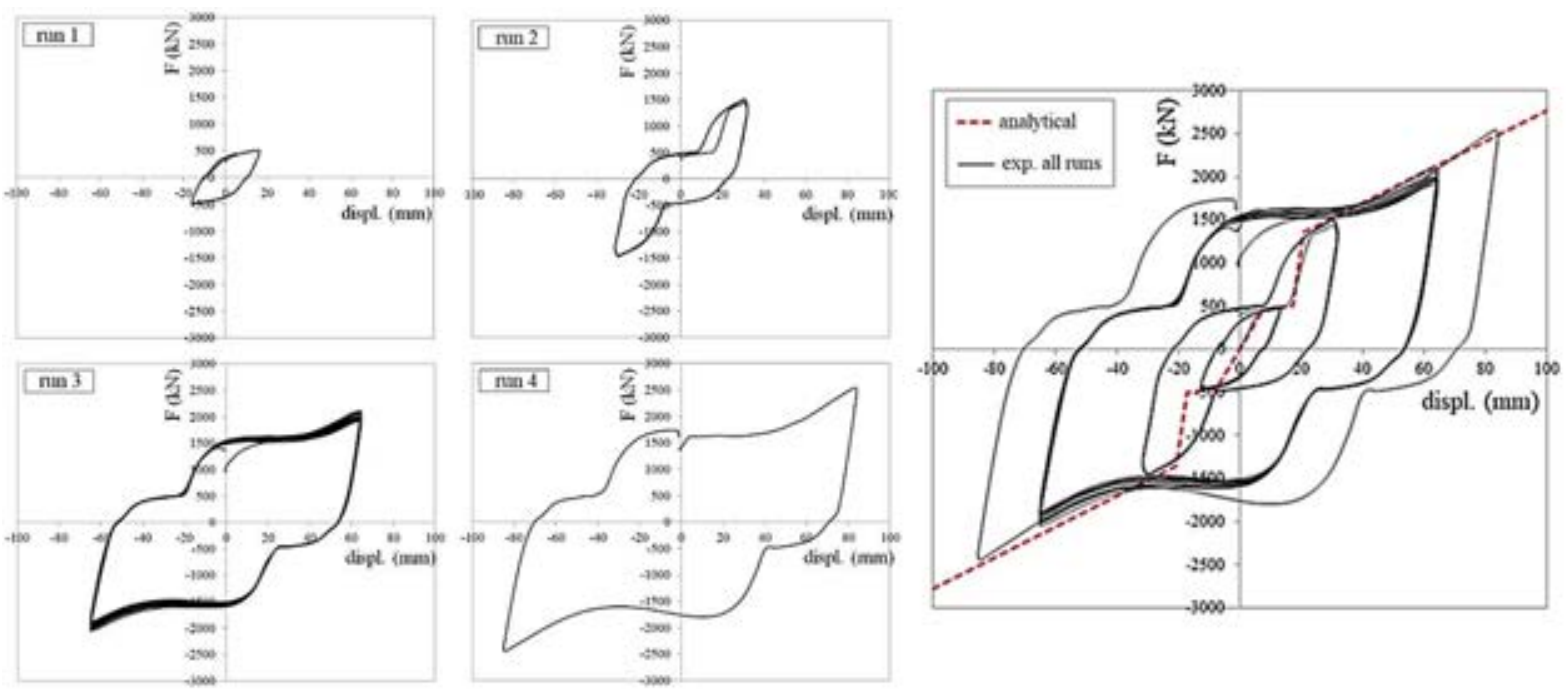

Figure 5: Recorded experimental loops. 


\section{DESIGN OF BRACED FRAMES THROUGH SPECTRAL ANALYSIS}

A recent study [23] has proven that the dynamic response, both in terms of maximum displacement and peak acceleration at roof level, of a multi-storey frame implementing the novel AHDs, can be predicted by means of simple iterative response spectrum analyses, where both the bare frame and the dissipative braces are schematized by means of linear equivalent SDOF systems. The basic assumption of this calculation method is the "a-priori knowledge" of the structural properties of the bare frame. This is always typical of retrofit-projects while for new buildings can be achieved through a preliminary design of the bare frame (e.g. accounting for the gravitational loads only). A modal analysis is hence performed to assess the participation factor $\Gamma=m^{*} / \sum m_{i} \phi_{i}^{2}$ and the participating mass $m^{*}=\sum m_{i} \phi_{i}$ of the fundamental mode shape. The lateral capacity of the bare frame is also appraised through nonlinear static (pushover) analyses under constant gravity loads and monotonically increasing horizontal loads (Fig. 6-left). Two distributions of lateral loads are considered, namely a "modal" pattern (resembling a triangular height-wise profile) and an "uniform" pattern as per EC8 provisions [1]. Among the two obtained capacity curves (base-shear $F$ versus control-point displacement $d$ ), the one associated to lowest strength is then processed (Fig. 6-right) in accordance with Annex B of EC8 [1]. The pushover curve $(F ; d)$ of the MDOF system is then scaled by the modal participation factor $\Gamma$ to obtain the capacity curve $F^{*}-d^{*}$ of the equivalent single-degree-of-freedom (SDOF) system $\left(F^{*}=\frac{F}{\Gamma} ; d^{*}=\frac{d}{\Gamma}\right)$. For clarity, hereinafter the quantities with superscript "*" will refer to equivalent SDOF systems, and quantities devoid of suffix will refer to real MDOF systems. The yield force $F_{y, F}^{*}$, yield $d_{y, F}^{*}$, and ultimate displacement $d_{u, F}^{*}$ (where subscript " $F$ " stands for "frame") are determined under the equal energy criterion assuming an ideal elastic-perfectly plastic force-displacement relationship.
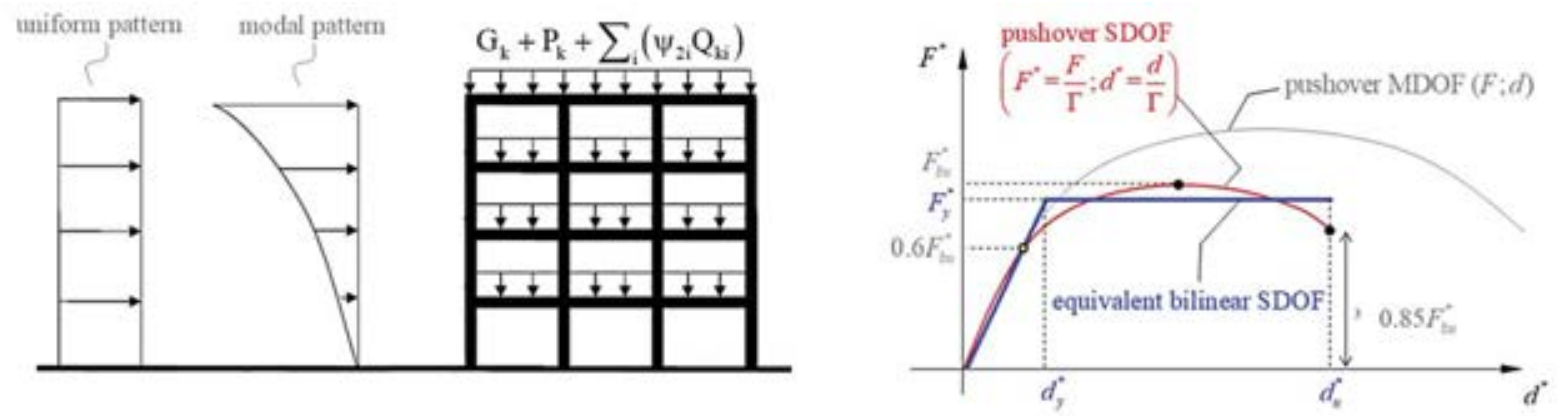

Figure 6: Qualitative representation of a pushover analysis (left) and definition of equivalent elastic-perfectly plastic SDOF system of the bare-frame (right).

Given a certain displacement demand $\left(d_{\text {max }}^{*}\right)$ of the seismic motion, the effective stiffness $\left(k_{e f f, F}^{*}\right)$, and ductility demand $\left(\mu_{F}^{*}\right)$ of the bare frame are calculated as:

$$
\begin{aligned}
& k_{e f f, F}^{*}=\left\{\begin{array}{lr}
k_{e l, F}^{*}=F_{y, F}^{*} / d_{y, F}^{*} & d_{\text {max }}^{*} \leq d_{y, F}^{*} \\
F_{y, F}^{*} / d_{\text {max }}^{*} & d_{y, F}^{*}<d_{\text {max }}^{*} \leq d_{u, F}^{*}
\end{array}\right. \\
& \mu_{F}^{*}=\left\{\begin{array}{rr}
1 & d_{\text {max }}^{*} \leq d_{y, F}^{*} \\
d_{\text {max }}^{*} / d_{y, F}^{*} & d_{y, F}^{*}<d_{\text {max }}^{*} \leq d_{u, F}^{*}
\end{array}\right.
\end{aligned}
$$


In particular, it has been recently proven [23] that the design parameters of the AHD can be iteratively adjusted in order to achieve a desired displacement target at ULS $\left(d_{\text {targ,ULS }}^{*}\right)$ selected between two possible ranges: (1) $d_{\text {targ,ULS }}^{*} \leq d_{y, F}^{*}$ when the goal is to maintain the frame in the elastic range; (2) $d_{y, F}^{*}<d_{\text {targ, } U L S}^{*}<d_{u, F}^{*}$ when a certain level of plasticization of frame can be accepted.

The spectral analysis is then carried out approximating the response of the braced frame through two linear equivalent SDOF systems working in parallel (Fig. 7-left) and accounting for the frame $\left(F^{*}\right)$ and the damper $\left(D^{*}\right)$ responses. The effective vibration period of the braced frame $\left(T_{e f f, F+D}^{*}\right)$ is conventionally calculated as:

$$
T_{e f f, F+D}^{*}=2 \pi \sqrt{\frac{m^{*}}{\left(k_{e f f, F}^{*}+k_{e f f, D}^{*}\right)}}
$$

where $k_{e f f, D}^{*}$ is the effective lateral stiffness of the AHD (whose definition is given in next Section).

Adapting the original formulations for "in parallel damping mechanisms" [24], the equivalent viscous damping of the braced frame $\left(\xi_{e q, F+D}^{*}\right)$ can be calculated through the following weighted average [25]:

$$
\xi_{e q, F+D}^{*}=\xi_{e l, F}^{*}+\frac{\xi_{e q, F}^{*} \cdot E_{c u m, F}^{*}+\xi_{e q, D}^{*} \cdot E_{c u m, D}^{*}}{E_{c u m, F}^{*}+E_{c u m, D}^{*}}
$$

being: (a) $\xi_{e l, F}^{*}$ the viscous damping offered by the frame in the elastic range (typically $5 \%$ and $2 \%$ for r.c. or steel structures, respectively); (b) $E_{c u m, F}^{*}$ and $E_{c u m, D}^{*}$ the energy dissipated by the frame and the AHD, respectively.

The estimation of the equivalent viscous damping $\left(\xi_{e q, D}^{*}\right)$ developed by the AHD is argued in the next Section while the one offered by frame $\left(\xi_{e q, F}^{*}\right)$ is calculated as [26]:

$$
\xi_{e q, F}^{*}=\frac{a}{\pi} \cdot\left(1-\frac{1}{\mu_{F}^{* b}}\right) \cdot\left(1+\frac{1}{\left(T_{e f f, F+D}^{*}+c\right)^{d}}\right) \cdot \frac{1}{N}
$$

being: (a) $N=1+\left[1 /(0.5+c)^{d}\right]$; (b) $a=140, b=0.5, c=0.85, d=2$.

For a generic set of AHD design parameters, i.e. $i^{\text {th }}$ couple of parameters $\left(T_{e f f, F+D}^{*}, \xi_{e q, F+D}^{*}\right)^{(i)}$, the peak displacement of the braced frame is obtained by reducing the elastic (viscous damping $5 \%)$ spectral displacement $\left(S_{d, U L S}\left(T_{e f f, F+D}^{*}, 5 \%\right)\right)$ through the spectral reduction factor $(\eta)$ proposed in [24]:

$$
\left\{\begin{array}{l}
S_{d, U L S}\left(T_{e f f, F+D}^{*}, \xi_{e q, F+D}^{*}\right)^{(i)}=\frac{1}{\eta^{(i)}} \cdot S_{d, U L S}\left(T_{e f f, F+D}^{*}, 5 \%\right) \\
\eta^{(i)}=\sqrt{7 /\left(2+\xi_{e q, F+D}^{*}{ }^{(i)}\right)}
\end{array}\right.
$$

The mechanical parameters of the $\operatorname{AHD}\left(F_{y, D 1}^{*}, F_{y, D 2}^{*}, k_{e l, D 1}^{*}, k_{p l, D 1}^{*}, k_{e l, D 2}^{*}, k_{p l, D 2}^{*}, d_{G}^{*}\right)$ are hence iteratively varied (Fig. 7, right) until the spectral displacement of the braced frame converges to the design target $\left(\left|S_{d, U L S}\left(T_{e f f, F+D}^{*}, \xi_{e q, F+D}^{*}\right)^{(i)}-d_{\text {targ }, U L S}^{*}\right| \leq t o l\right.$, being tol a small enough tolerance parameter (e.g. tol $\left.=0.01 \cdot d_{\text {targ }, U L S}^{*}\right)$. 
Since the iterative design process could seem not trivial (seven variable parameters), some "good practice" criteria that guide designers and practitioners to a fast identification of the optimal layout of the AHD are provided in Section 4.2. Moreover, in Section 5, specific rules for the spatial distribution of the AHD units at the different storey levels of the MDOF frame are also provided and applied to a real case-study building.
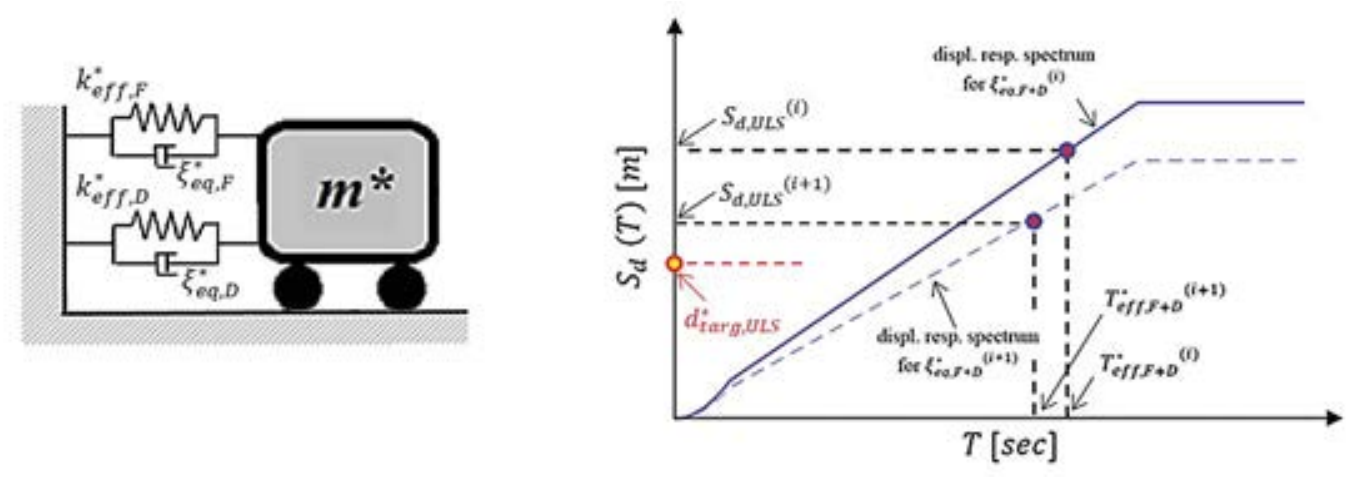

Figure 7: Proposed calculation method: rheological model (left) and iterative response spectrum analyses (right).

\subsection{Linear equivalent properties of the AHD}

According to a good design practice, it is assumed hereafter that beam elements used to link the AHDs to the bare frame are very stiff and hence, even under severe earthquakes, undergo neglibible elastic deformations without affecting the effective stiffness offered by the dampers [23]. Otherwise, a simple approach to account for the flexibility of link elements can be found in [19].

The effective stiffness provided by the AHD $\left(k_{e f f, D}^{*}\right)$ reflects the "two-steps" hysteretic behaviour of the device (see Fig. 8) and, depending on the displacement demand $\left(d_{\max }^{*}\right)$ and strength demand $\left(F_{\max }^{*}\right)$ of the occuring earthquake (i.e. SLS or ULS), can be calculated as:

$$
k_{e f f, D}^{*}= \begin{cases}\frac{F_{y, 1}^{*}+k_{p l, 1}^{*} \cdot\left(d_{\text {max }}^{*}-d_{y, 1}^{*}\right)}{d_{\text {max }}^{*}} & d_{\text {max }}^{*} \leq d_{E S}^{*}(\text { at } S L S) \\ \frac{F_{E S}^{*} d_{E S}^{*}+F_{\text {max }}^{*}\left(d_{\text {max }}^{*}-d_{E S}^{*}\right)}{d_{\text {max }}^{2}} & d_{\text {max }}^{*} \geq d_{y 2}^{*} \quad(\text { at } U L S)\end{cases}
$$

It is worth noting that, embracing the approach proposed in a recent study in [25], Eq. 7-b can be obtained equalizing the total elastic energy stored in the minor and major dissipative cores to the elastic energy stored in a virtually equivalent linear spring $\left(E_{e, D}^{*}=E_{e, D 1}^{*}+E_{e, D 2}^{*}\right)$ :

$$
\frac{1}{2} k_{e f f, D}^{*} d_{\text {max }}^{*}=\frac{1}{2} F_{E S}^{*} d_{E S}^{*}+\frac{1}{2} F_{\text {max }}^{*}\left(d_{\text {max }}^{*}-d_{E S}^{*}\right)
$$

One can note that Eq. 8 alternatively means that the sum of the two blue shaded areas shown in Fig. 8-right is equal to the grey shaded one.

Despite an apparently simple "in series" arrangement of the two hysteretic cores, the effective damping offered by the AHD obeys to slightly more complex rules. Indeed, during minor SLS earthquakes $\left(d_{\max }^{*} \leq d_{E S}^{*}\right)$, only the minor core (D1) is plastically engaged providing a certain energy dissipation (ductility level $\mu_{D 1}^{*}>1$ ) while the major (D2) acts as a non-dissipative link $\left(\mu_{D 2}^{*}=1\right)$. On the contrary, under more demanding ULS displacements $\left(d_{\text {max }}^{*}>d_{y, 2}^{*}\right)$, the major core is activated experiencing a certain ductility demand $\left(\mu_{D 2}^{*}>1\right)$ 
while the deformation of the minor core is freezed at the maximum level allowed by the gapconnector $\left(\mu_{D 1}^{*}=d_{E S}^{*} / d_{y, 1}^{*}\right)$ :

$$
\begin{gathered}
\mu_{D 1}^{*}= \begin{cases}1 & d_{\text {max }}^{*} \leq d_{y, 1}^{*} \\
d_{\text {max }}^{*} / d_{y, 1}^{*} & d_{y, 1}^{*}<d_{\text {max }}^{*} \leq d_{E S}^{*} \\
d_{E S}^{*} / d_{y, 1}^{*} & d_{\text {max }}^{*}>d_{E S}^{*}\end{cases} \\
\mu_{D 2}^{*}= \begin{cases}1 & d_{\text {max }}^{*} \leq d_{y, 2}^{*} \\
\frac{\left(d_{\text {max }}^{*}-d_{G}^{*}\right)}{\left(d_{y, 2}^{*}-d_{G}^{*}\right)} & d_{\text {max }}^{*}>d_{y, 2}^{*}\end{cases}
\end{gathered}
$$

The equivalent viscous damping offered by the minor $\left(\xi_{e q, D 1}^{*}\right)$ and major $\left(\xi_{e q, D 2}^{*}\right)$ dissipative cores are calculated by means of the formulation proposed in [26] for bilinear hysteretic systems:

$$
\xi_{e q, D(i)}^{*}=\frac{a}{\pi} \cdot\left(1-\frac{1}{\mu_{D(i)}^{*} b}-0.1 \cdot r_{(i)} \cdot \mu_{D(i)}^{*}\right) \cdot\left(1+\frac{1}{\left(T_{e f f, F+D}^{*}+c\right)^{d}}\right) \cdot \frac{1}{N}
$$

where: (a) the subscript " $(i)$ " refers to the minor $(i=1)$ or major $(i=2)$ core, alternatively; (b) $N=1+\left[1 /(0.5+c)^{d}\right]$; (c) $a=140, b=0.5, c=0.85, d=2$; (d) $\mu_{D i}^{*}$ and $r_{i}=$ $k_{p l, D i}^{*} / k_{e l, D i}^{*}$ are the ductility demand and hardening ratio, respectively.

Eventually, the overall equivalent viscous damping offered by the damper $\left(\xi_{e q, D}^{*}\right)$ is calculated through this weighted average [25]:

$$
\xi_{e q, D}^{*}=\frac{\xi_{e q, D 1}^{*} \cdot E_{c u m, D 1}^{*}+\xi_{e q, D 2}^{*} \cdot E_{c u m, D 2}^{*}}{E_{c u m, D 1}^{*}+E_{c u m, D 2}^{*}}
$$

being $E_{c u m, D 1}^{*}$ and $E_{c u m, D 2}^{*}$ the energy dissipated by the minor and major hysteretic core (Fig. 9), respectively.
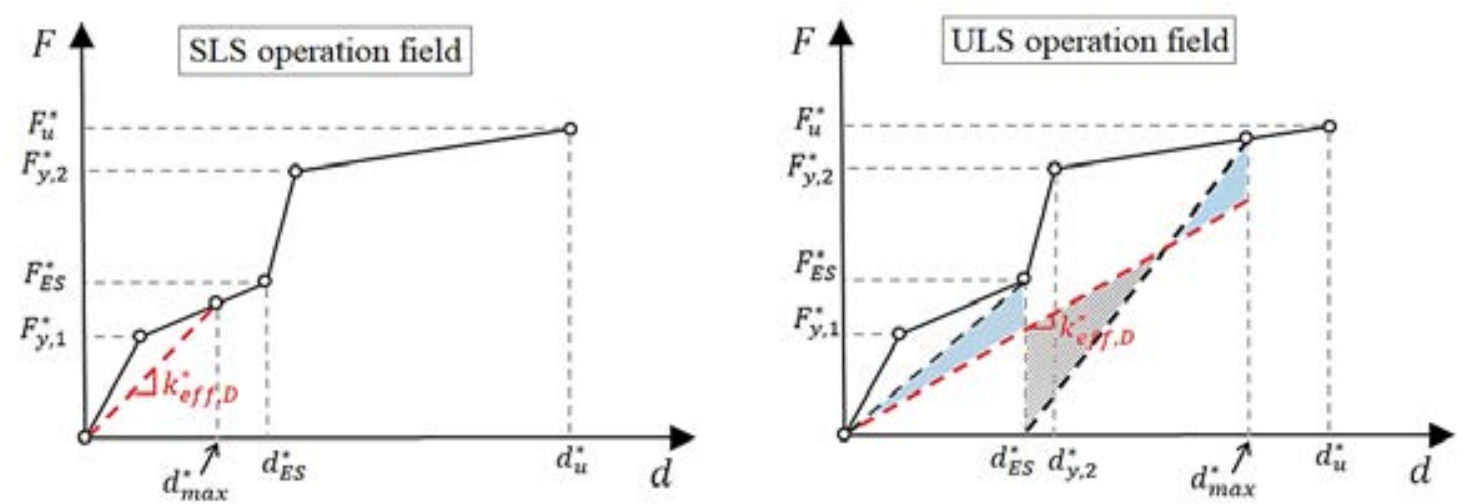

Figure 8: Definition of the damper effective stiffness for minor SLS displacements (left, $d_{\text {max }}^{*} \leq d_{E S}$ ), and severe ULS displacements (right, $d_{\max }^{*} \geq d_{y, 2}$ ). 

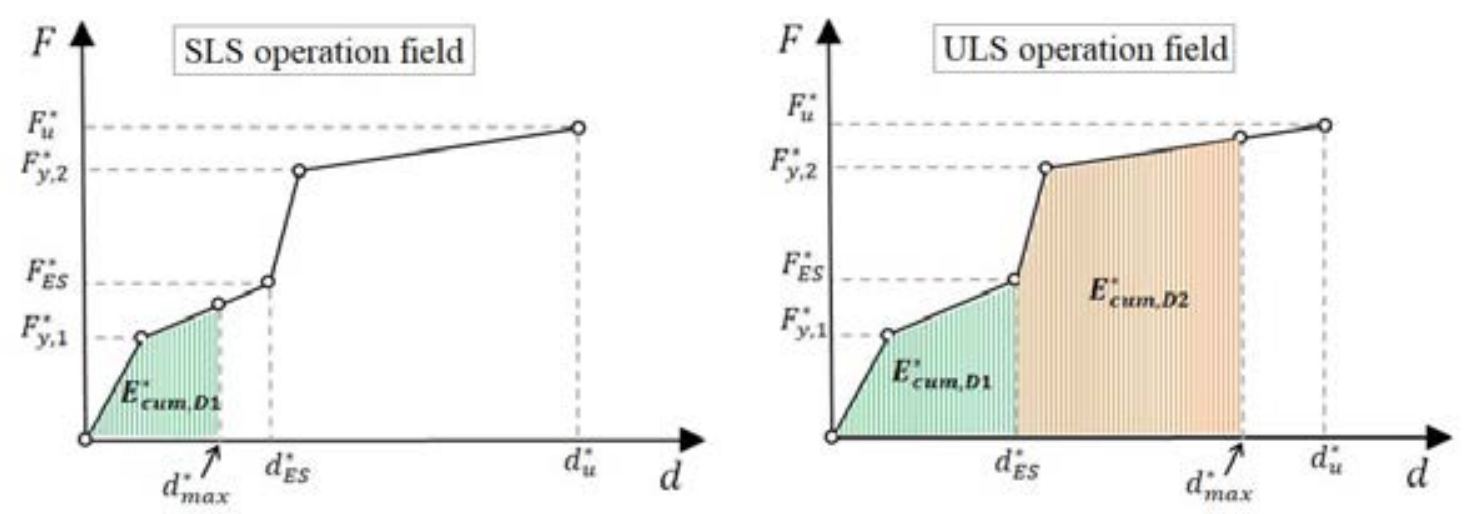

Figure 9: Definition of the energy dissipated by the two hysteretic cores for minor SLS displacements (left, $d_{\max }^{*} \leq d_{E S}$ ), and severe ULS displacements (right, $d_{\max }^{*} \geq d_{y, 2}$ ).

\subsection{Simplified set of AHD design parameters}

Due to the large number (seven) of the AHD design parameters $\left(F_{y, D 1}^{*}, F_{y, D 2}^{*}, k_{e l, D 1}^{*}, k_{e l, D 2}^{*}\right.$, $k_{p l, D 1}^{*}, k_{p l, D 2}^{*}$, and $\left.d_{G}^{*}\right)$, the definition of the optimal damper layout could seem not easy. To overcome this issue, some criteria to simplify/reduce the variable parameters are provided hereafter. Within this framework, the ratios $\alpha_{F}, \alpha_{k}$, and $r$ are introduced to link the design parameters of the two hysteretic cores and those of the bare frame [23]:

$$
\left\{\begin{array}{l}
\alpha_{F}=F_{y, D 1}^{*} / F_{y, D 2}^{*} \\
\alpha_{k}=k_{e l, D 1}^{*} / k_{e l, F}^{*} \\
r=k_{p l, D 1}^{*} / k_{e l, D 1}^{*}=k_{p l, D 2}^{*} / k_{e l, D 2}^{*}
\end{array}\right.
$$

In particular, at designer's discretion, $\alpha_{k}$ and $r$ can be selected within the ranges $\left(\alpha_{F}=0.3-\right.$ $0.6, \alpha_{k}=2-15$, and $r=0.01-0.10$ ) suggested in [23] leading to:

$$
\begin{aligned}
& \left\{\begin{array}{l}
F_{y, D 1}^{*}=\alpha_{F} \cdot F_{y, D 2}^{*} \\
k_{e l, D 1}^{*}=\alpha_{k} \cdot k_{e l, F}^{*} \\
k_{e l, D 2}^{*}=\left(\alpha_{k} / \alpha_{F}\right) \cdot k_{e l, F}^{*} \\
k_{p l, D 1}^{*}=r \cdot \alpha_{k} \cdot k_{e l, F}^{*} \\
k_{p l, D 2}^{*}=r \cdot\left(\alpha_{k} / \alpha_{F}\right) \cdot k_{e l, F}^{*}
\end{array}\right.
\end{aligned}
$$

Moreover, accomplishing to the "adaptive working principle" of the AHD providing the exclusive engagement of the minor (D1) core during weak SLS events, a suitable criterion for the selection of the width $\left(d_{G}^{*}\right)$ of the gap-connector is [23]:

$$
d_{G}^{*}=\gamma_{x} \cdot \gamma_{b} \cdot S_{d, S L S}\left(T_{e f f, F+D}^{*}, \xi_{e q, F+D}^{*}\right)
$$

being: (a) $S_{d, S L S}\left(T_{e f f, F+D}^{*}, \xi_{e q, F+D}^{*}\right)$ the spectral displacement calculated at SLS; (b) $\gamma_{x}=1.1$, and $\gamma_{b}=1.2$ a reliability and a safety factor, respectively [1].

The "good practice" design assumptions described in this Section allow to reduce the number of variable parameters to the couple $\left(F_{y, D 2}^{*} ; \alpha_{F}\right)$ leading to a fast identification of most suitable AHD layout. 


\section{A CASE-STUDY}

In this Section, a seismic retrofit intervention of the "Piastra building" of the hospital complex of Lamezia Terme, a small city located in southern Italy, is designed through the previously proposed iterative spectral analyisis. The beneficial effects offered by the AHDs, compared to traditional bilinear hysteretic dampers (BHDs), are discussed and quantified. For sake of simplicity, only the longitudinal frame of the "block C" is considered hereafter (Fig. 10 -a). This building, erected in the early 70 's, features a quite flexible r.c. frame (fundamental period equal to 1.06s) and would not be capable to survive the ULS design earthquake [4].

The reference retrofitting solution through conventional BHDs has been already proposed elsewhere [5]. In the same study, the characteristic parameters of both the real MDOF and the equivalent SDOF system of the bare frame are provided (Table 3 ).

The new retrofitting solution provides the replacement of the traditional BHDs with the innovative AHDs designed to ensure an unaltered degree of structural protection under severe ULS events, and offer an enhanced seismic response to minor SLS earthquakes. In this regard, according to the provisions of the Italian Building code [27], a severe "SLV" (ULS level) and a weak "SLO" (SLS level) design spectrum, featuring respectively $P G A=0.45 g$ and $P G A=0.17 g$, were defined considering a topographic category $\mathrm{T} 1$, a nominal life of the building $V_{N}=100 y e a r s$ (corresponding to a reference period $V_{R}=c_{u} \cdot V_{N}=200 y e a r s$ ), and foundation-soil type B.

By analogy with the design-assumption of traditional BHDs [5], the ULS displacement target of the new retrofit-project is set to $d_{\text {targ,ULS }}=50 \mathrm{~mm}\left(d_{\text {targ,ULS }}^{*}=d_{\text {targ,ULS }} / \Gamma=\right.$ $36.8 \mathrm{~mm}$ ) in order to maintain the frame in the elastic field and avoid the hammering with the adjacent "block B". Besides this target, thanks to the iterative spectral procedure and the design criteria provided in the previous Section, the following set of AHD design parameters is detected to ensure minimal spectral accelerations under weak but frequent SLS earthquakes [23]: $\quad F_{y, D 2}^{*}=7300 \mathrm{kN}, \alpha_{F}=0.38, \alpha_{k}=15, r=0.075$, and $d_{G}^{*}=14 \mathrm{~mm}$. The relevant effective period and equivalent viscous damping of the braced frame are: (i) at ULS design level, $T_{e f f, F+D}^{*}=0.53 \mathrm{~s}$, and $\xi_{e q, F+D}^{*}=29.2 \%$; (ii) at SLS design level, $T_{e f f, F+D}^{*}=0.46 \mathrm{~s}$, and $\xi_{e q, F+D}^{*}=23.7 \%$. The (equivalent SDOF) design parameters of the selected AHD layout and those of the original BHD [5] are compared in Table 4.

\begin{tabular}{|c|c|c|c|c|}
\hline \multicolumn{5}{|c|}{ real MDOF frame } \\
\hline storey & $\begin{array}{l}\mathbf{m}_{\mathbf{i}} \\
\text { (ton) }\end{array}$ & $\begin{array}{l}\phi_{i} \\
(-)\end{array}$ & $\begin{array}{l}F_{y, F, i} \\
(k N)\end{array}$ & $\begin{array}{l}\mathbf{k}_{\mathrm{el}, \mathrm{F}, \mathrm{i}} \\
(\mathrm{kN} / \mathbf{m m})\end{array}$ \\
\hline 1 & 1333 & 0.28 & 4703 & 344 \\
\hline 2 & 1302 & 0.63 & 3886 & 187 \\
\hline 3 & 954 & 1.00 & 2090 & 75 \\
\hline \multicolumn{5}{|c|}{ equivalent SDOF system } \\
\hline $\begin{array}{l}\Gamma \\
(-)\end{array}$ & $\begin{array}{l}\mathrm{m}^{*} \\
\text { (ton) }\end{array}$ & $\begin{array}{l}\mathbf{F}_{\mathbf{y}, \mathbf{F}}^{*} \\
(\mathbf{k N})\end{array}$ & $\begin{array}{l}d_{y, F}^{*} \\
(\mathbf{m m})\end{array}$ & $\begin{array}{l}\mathbf{k}_{\mathrm{el}, \mathbf{F}}^{*} \\
(\mathbf{k N} / \mathbf{m m})\end{array}$ \\
\hline 1.36 & 2148 & 4704 & 62.3 & 75.5 \\
\hline
\end{tabular}

Table 3: Characteristic parameters of the bare frame: real MDOF system $(\mathrm{F})$ and equivalent SDOF one $\left(\mathrm{F}^{*}\right)$. 


\begin{tabular}{|c|c|c|c|c|c|c|c|c|c|}
\hline \multicolumn{7}{|c|}{ novel AHD } & \multicolumn{3}{|c|}{ traditional BHD } \\
\hline $\begin{array}{l}\mathbf{F}_{\mathrm{y}, \mathrm{D} 1}^{*} \\
(\mathrm{kN})\end{array}$ & $\begin{array}{l}\mathbf{F}_{\mathbf{y}, \mathbf{D} 2}^{*} \\
(\mathbf{k N})\end{array}$ & $\begin{array}{l}\mathbf{k}_{\mathrm{el}, \mathrm{D} 1}^{*} \\
(\mathbf{k N} / \mathbf{m m})\end{array}$ & $\begin{array}{l}\mathbf{k}_{\mathrm{el}, \mathrm{D} 2}^{*} \\
(\mathbf{k N} / \mathbf{m m})\end{array}$ & $\begin{array}{l}\mathbf{k}_{\mathrm{pl}, \mathrm{D} 1}^{*} \\
(\mathrm{kN} / \mathbf{m m})\end{array}$ & $\begin{array}{l}\mathbf{k}_{\mathrm{pl}, \mathrm{D} 2}^{*} \\
(\mathbf{k N} / \mathbf{m m})\end{array}$ & $\begin{array}{l}\mathbf{d}_{\mathbf{G}}^{*} \\
(\mathbf{m m})\end{array}$ & $\begin{array}{l}\mathbf{F}_{\mathbf{y}, \mathbf{D}}^{*} \\
(\mathbf{k N})\end{array}$ & $\begin{array}{l}\mathbf{k}_{\mathrm{el}, \mathrm{D}}^{*} \\
(\mathrm{kN} / \mathrm{mm})\end{array}$ & $\begin{array}{l}\mathbf{k}_{\mathrm{pl}, \mathrm{D}}^{*} \\
(\mathrm{kN} / \mathbf{m m})\end{array}$ \\
\hline 2760 & 7300 & 1133 & 2998 & 85.0 & 224.9 & 14.0 & 7000 & 1124 & 28.1 \\
\hline
\end{tabular}

Table 4: Design parameters of the selected AHD compared to those of the traditional BHD (eq. SDOF systems).

Once defined the design parameters of the equivalent SDOF of the AHD, the the yielding force of the minor $\left(F_{y, D 1, i}\right)$ and major $\left(F_{y, D 2, i}\right)$ cores of the physical AHD devices installed at the $i^{\text {th }}$ storey of the real MDOF frame are sized through this rule [23]:

$$
\left\{\begin{array}{l}
F_{y, D 1, i}=\left(\frac{F_{y, F, i}}{F_{y, F}^{*}}\right)\left(\frac{F_{y, D 1}^{*}}{n_{A H D, i} \cdot \cos \vartheta_{i}}\right) \\
F_{y, D 2, i}=\left(\frac{F_{y, F, i}}{F_{y, F}^{*}}\right)\left(\frac{F_{y, D 2}^{*}}{n_{A H D, i} \cdot \cos \vartheta_{i}}\right)
\end{array}\right.
$$

and similarly for the elastic stiffness of the two cores:

$$
\left\{\begin{array}{l}
k_{e l, D 1, i}=\left(\frac{k_{e l, F, i}}{k_{e l, F}^{*}}\right)\left(\frac{k_{e l, D 1}^{*}}{n_{A H D, i} \cdot \cos ^{2} \vartheta_{i}}\right) \\
k_{e l, D 2, i}=\left(\frac{k_{e l, F, i}}{k_{e l, F}^{*}}\right)\left(\frac{k_{e l, D 2}^{*}}{n_{A H D, i} \cdot \cos ^{2} \vartheta_{i}}\right)
\end{array}\right.
$$

resulting in the following plastic stiffnesses:

$$
\left\{\begin{array}{l}
k_{p l, D 1, i}=r \cdot k_{e l, D 1, i} \\
k_{p l, D 2, i}=r \cdot k_{e l, D 2, i}
\end{array}\right.
$$

being: (a) $F_{y, F, i}$ and $k_{e l, F, i}$ the overall lateral yielding-strength and elastic stiffness of the columns at the $\mathrm{i}^{\text {th }}$ storey level [19], respectively; (b) $n_{A H D, i}$ the number of AHD units installed at the same level; (c) $\vartheta_{i}$ the inclination angle of the dissipative braces (Fig. 10,b).

The "storey-distribution" of $d_{G A P}^{*}$ among the AHD units installed at the different storey levels is assumed to reflect the fundamental mode shape [23]:

$$
d_{G, i}=\Gamma_{\phi_{1}} \cdot\left(\phi_{1, i}-\phi_{1, i-1}\right) \cdot d_{G A P}^{*} \cdot \cos \vartheta_{i}
$$

The complete set of design parameters of the real AHD units installed along the diagonal braces of each storey level are listed in Table 5.

The effectiveness of the new retrofitting solution is proven through NLTH analyses carried out in OpenSees FEM code [28] developing a specific modelling strategy for the AHD units [23]. Two sets of seven ground motion records (Fig. 11), one for the SLS and one for the ULS design spectrum, were identified by means of the software REXEL [29] enforcing the "spectrum compatibility" criterion in the range [0.15-2.0s]. According to the reference Standard [27], the structural integrity of the frame is checked at ULS and the serviceability of the hospital at SLS considering the average response over the seven independent history analyses. 
E. Gandelli, J. Distl, P. Huber, and C. Braun

\begin{tabular}{lllllllll}
\hline level & $\begin{array}{l}\mathbf{n}_{\text {AHD,i }} \\
(-)\end{array}$ & $\begin{array}{l}\boldsymbol{\vartheta}_{\mathbf{i}} \\
\left({ }^{\circ}\right)\end{array}$ & $\begin{array}{l}\mathbf{F}_{\mathbf{y}, \mathbf{D} 1, \mathbf{i}} \\
(\mathbf{k N})\end{array}$ & $\begin{array}{l}\mathbf{F}_{\mathbf{y}, \mathbf{D} 2, \mathbf{i}} \\
(\mathbf{k N})\end{array}$ & $\begin{array}{l}\mathbf{k}_{\mathbf{e l}, \mathbf{D} 1, \mathbf{i}} \\
(\mathbf{k N} / \mathbf{m m})\end{array}$ & $\begin{array}{l}\mathbf{k}_{\mathbf{e l , D 2 , i}} \\
(\mathbf{k N} / \mathbf{m m})\end{array}$ & $\begin{array}{l}\boldsymbol{r} \\
(\mathbf{\%})\end{array}$ & $\begin{array}{l}\mathbf{d}_{\mathbf{G}, \mathbf{i}} \\
(\mathbf{m m})\end{array}$ \\
\hline 1 & 12 & 54.8 & 399 & 1055 & 1293 & 3423 & 7.5 & 3.1 \\
2 & 12 & 44.2 & 265 & 701 & 455 & 1205 & 7.5 & 4.8 \\
3 & 12 & 51.3 & 163 & 432 & 240 & 635 & 7.5 & 4.4 \\
\hline
\end{tabular}

Table 5: Design parameters of the different AHD units installed at each storey level.

(a)

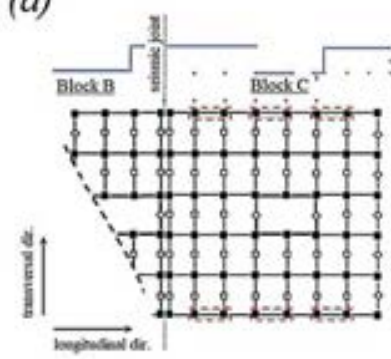

(b)

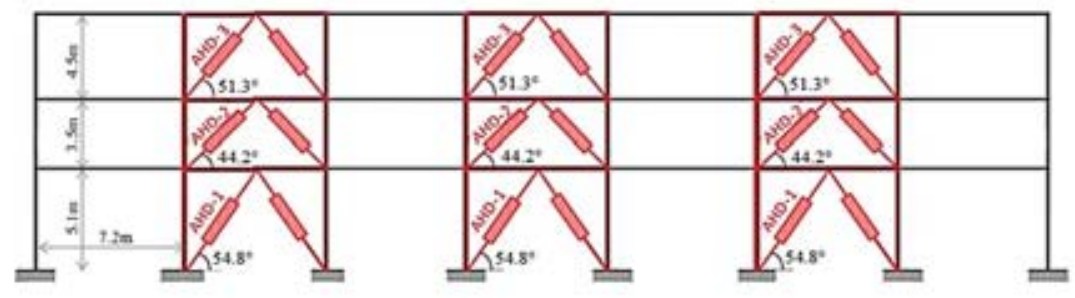

Figure 10: Spatial arrangement of the AHD units: (a) in-plan location; (b) vertical layout.
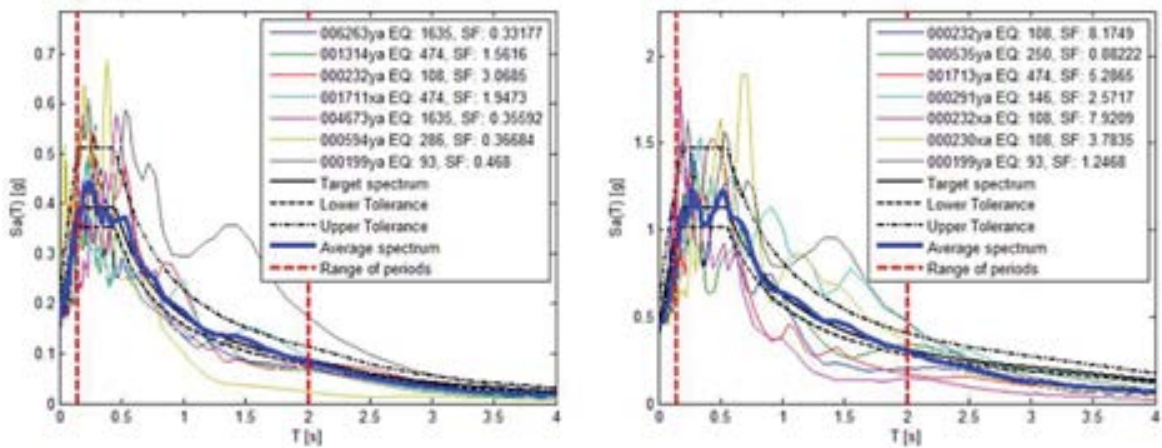

Figure 11: Selected ground motion records for NLTH analyses at SLS (left) and ULS (right).

According to the design assumption (i.e. $d_{\text {targ,ULS }}^{*}<d_{y, F}^{*}$ ), r.c elements of the braced frame react to the seismic shaking remaining always in their elastic range. This is witnessed by Fig. 12 that shows the calculated displacement envelopes over the storey levels: the aver-

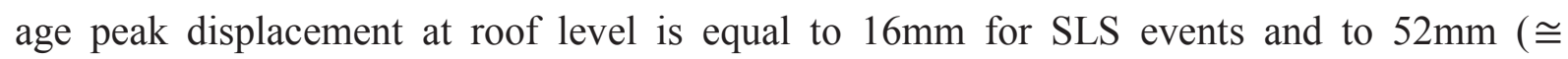
$\left.d_{\text {targULS }}\right)$ for ULS earthquakes. In particular at SLS, despite the "AHD solution" is a bit more flexible than the "BHD solution" (16mm vs. $13 \mathrm{~mm}$ of peak displacement, respectively), thanks to the significant damping offered by the minor hysteretic core $\left(\xi_{e q, F+D}^{*}=23.7 \%\right)$, the displacement increase does not represent a hazard neither for "displacement-sensitive" nor for "drift-sensitive" NSCs. Indeed, as shown in Fig. 13-right, the largest inter-storey drift affects the $2^{\text {nd }}$ columns level with a peak of $0.17 \%$ (practically identical to $0.16 \%$ calculated for the "BHD solution") that is widely below the "immediate occupancy" average limits for both the weakest "drift-sensitive" NSC $(0.75 \%$ for infill walls) [3] and r.c. column elements $(0.66 \%)$ [7].

The enhanced protection level offered by the innovative AHDs is evident comparing the envelopes of PFAs at SLS (Fig. 13-left). The PFAs calculated at $3^{\text {rd }}$ storey level are $0.20 \mathrm{~g}$ and $0.42 \mathrm{~g}$ for the retrofitting solution implementing the AHDs and the BHDs, respectively. This 
achievement can be easily explained considering the lower effective period $\left(T_{e f f, F+D}^{*}=0.33 \mathrm{~s}\right)$ and minor equivalent viscous damping $\left(\xi_{e q, F+D}^{*}=8.9 \%\right)$ offered by common BHDs (i.e. stiffer structure with lower energy dissipation capacity). As shown in Fig. 14, the huge reduction $(-52 \%)$ of the PFAs leads also to markedly less demanding floor response spectra (calculated assuming a conventional viscous damping equal to 5\%). These plots allow to compare the actual acceleration experienced by all NSCs (characterized different fundamental periods) installed at the different storey levels. For all oscillation periods in the range $[0-4.0 \mathrm{~s}]$, the floor response spectrum of the new "AHD solution" lies practically always below that of the original "BHD solution" ensuring reduced peak values: $-20 \%,-55 \%$, and $-53 \%$ for NSCs installed at first, second, and third storey level, respectively. Compared to the response offered by traditional BHDs, one can therefore conclude that the innovative AHDs, besides an unaltered protection level for both structural and non-structural drift-sensitive elements, can guaranty a considerably enhanced safeguard of "acceleration-sensitive" elements leading to a more prompt operation of the building after the quake and to likely reduced repairing costs.
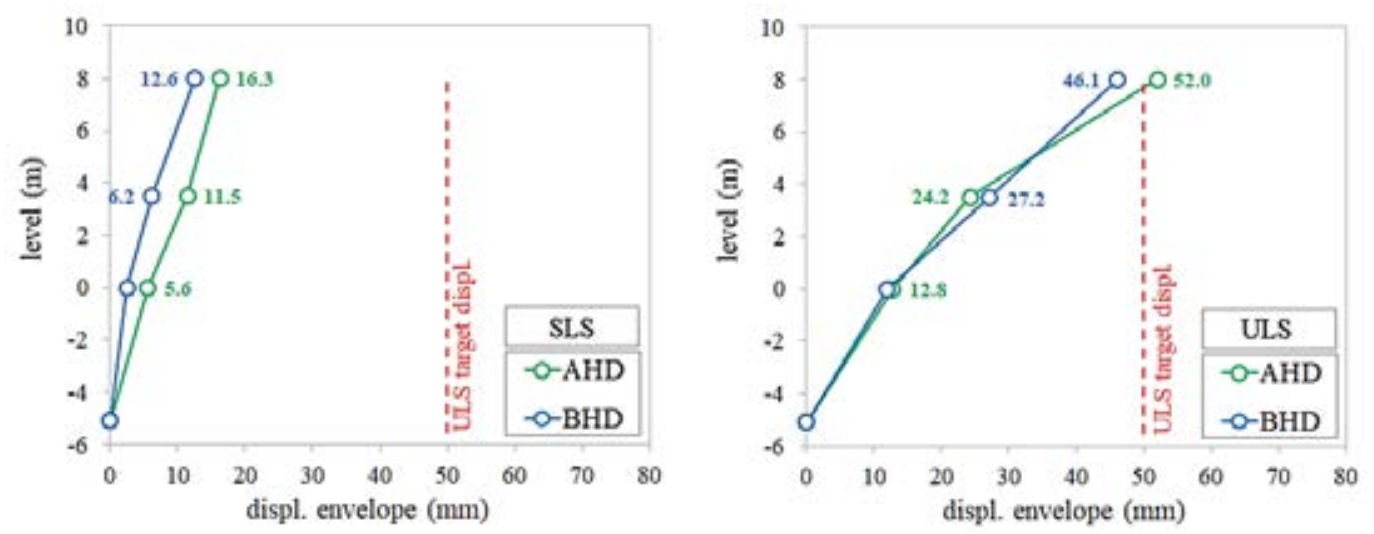

Figure 12: Average displacement envelopes calculated for the braced frame under SLS (left), and ULS (right) earthquakes.
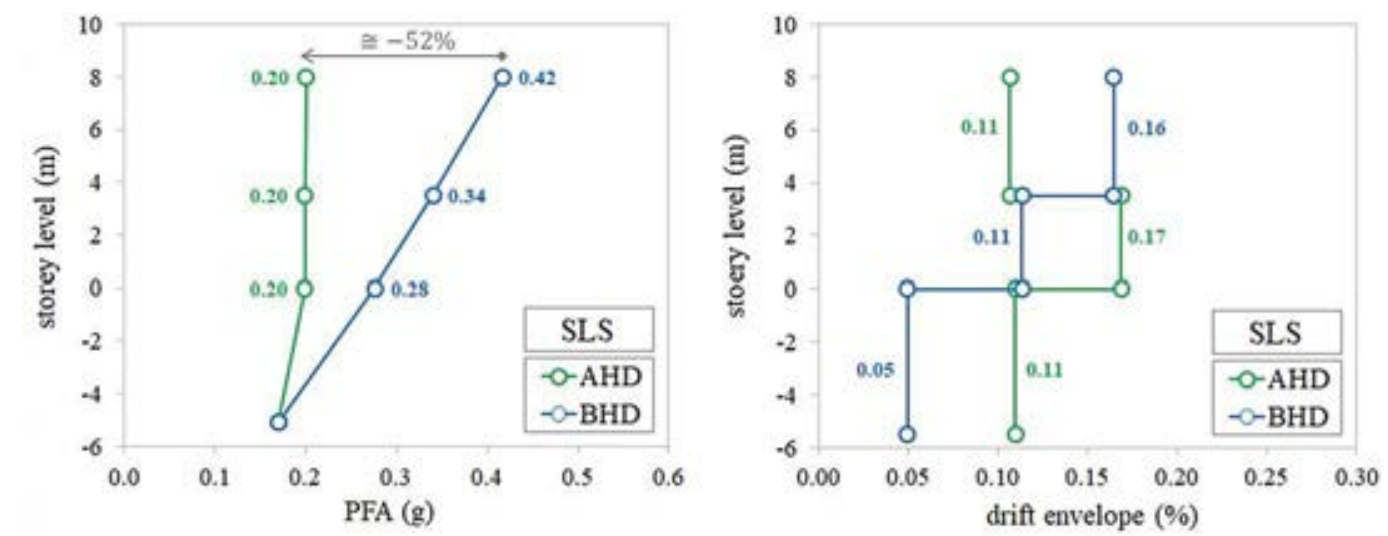

Figure 13: Average PFA (left) and inter-storey drift (right) envelopes calculated for SLS earthquakes. 

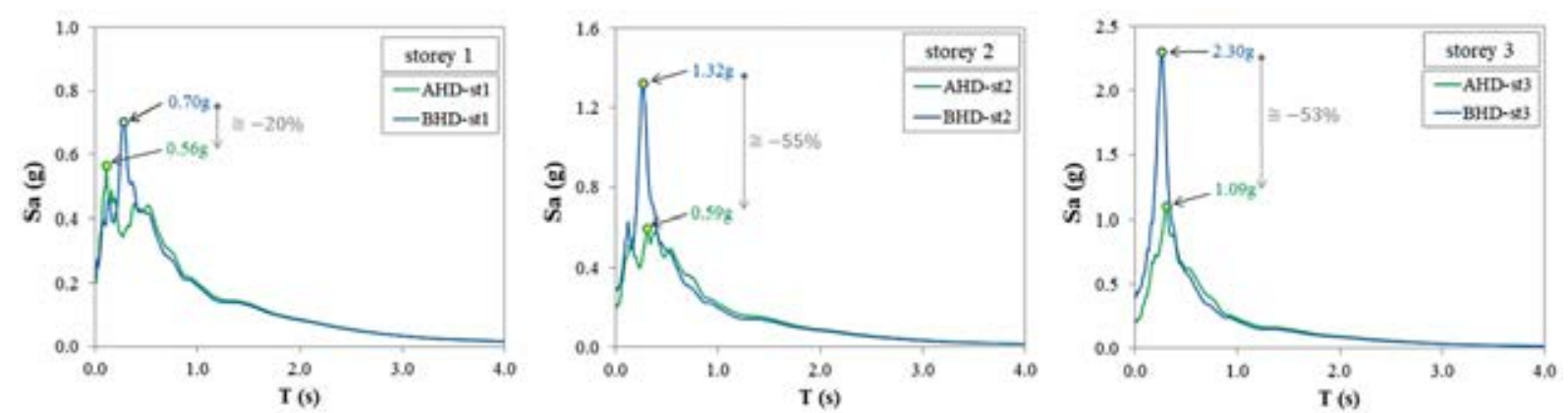

Figure 14: Average floor response spectra $(\xi=5 \%)$ calculated from acceleration time-histories obtained for SLS earthquakes: storey 1 (left), storey 2 (center), and storey 3 (right).

\section{CONCLUSIONS}

Traditional bilinear hysteretic dampers (BHDs) dampers are usually designed to guaranty the structural integrity of braced buildings under severe ULS seismic events. As a drawback, under weak but frequent SLS earthquakes, they practically behave as stiff springs causing high PFAs that are detrimental for "acceleration-sensitive" nonstructural components (NSCs).

To overcome this drawback, the innovative Adaptive Hysteretic Damper (AHD), capable to develop a two-steps hysteretic loop and to modulate its effective stiffness and damping based on the intensity of the occurring earthquake, has been presented claiming the following:

- results of experimental force-displacement tests have proven the reliability and robustness (i.e. stable response) of the device under repeated cyclic motions with increasing amplitudes;

- simple response spectrum analyses can be exploited for the design of braced buildings implementing the AHDs whose linear equivalent mechanical properties can be calculated through the analytical formulas provided in this paper;

- the main benefits arising from to the implementation of novel AHDs, rather than common BHDs, in braced frames have been quantified through NLTH analyses carried out on a case-study building. Very similar lateral displacements and inter-storey drifts envelopes have been calculated for the two structural systems, at both ULS and SLS design levels, resulting in the same protection level for structural and nonstructural sensitive elements. On the contrary, at SLS, the adoption of the new AHDs leads to markedly reduced peak floor (up to $-52 \%$ ) and spectral accelerations (up to -55\%) ensuring: (a) an enhanced protection of "acceleration-sensitive" NSCs; (b) a more prompt response of the building after the quake; (c) likely reduced repairing costs. 


\section{REFERENCES}

[1] CEN - Comité Européen de Normalisation, EN 1998-1 - Eurocode 8: Design of structures for earthquake resistance - Part 1: General rules, seismic actions and rules for buildings. Brussels, Belgium, 2004.

[2] M.J.N. Priestley, Performance based seismic design. 12th World Conference on Earthquake Engineering (WCEE). Auckland, New Zeeland, 2000.

[3] G. Lupoi, P. Franchin, A. Lupoi, P.E. Pinto, G.M. Calvi, Probabilistic Seismic Assessment for Hospitals and Complex-Social Systems. ROSE Research Report No. 2008/02. IUSS Press, 2008.

[4] E. Gandelli, V. Quaglini, P. Dubini, M.P. Limongelli, S. Capolongo, Seismic isolation retrofit of hospital buildings with focus on non-structural components. Ingegneria Sismica - International Journal of Earthquake Engineering, 36(2), 118-136, 2018.

[5] E. Gandelli, A. Taras, J. Distl, V. Quaglini, Seismic retrofit of hospitals by means of hysteretic braces: influence on acceleration-sensitive non-structural components. Frontiers in Built Environment - Earthquake Engineering section, 5, 2019.

[6] FEMA, Federal Emergency Management Agency, Earthquake Loss Estimation Methodology: HAZUS® Technical Manual. National Institute of Building Sciences, Washington, DC, 1999.

[7] A. Yakut, T. Solmaz, Performance based Displacement Limits for Reinforced Columns under Flexure. $15^{\text {th }}$ World Conference on Earthquake Engineering, Lisbon, Portugal, 2012.

[8] P.M. Calvi, Relative Displacement Floor Spectra for Seismic Design of Nonstructural Elements, Journal of Earthquake Engineering, 28(9), 979-993, 2014.

[9] C. Lima, E. Martinelli, Seismic Response of Acceleration-Sensitive Non-Structural Components in Buildings. Buildings, 9(1), 2018.

[10] R.I. Skinner, R.G. Tyler, A.J. Heine, W.H. Robinson. Hysteretic dampers for protection of structures from earthquakes. Bulletin of the New Zealand Society for Earthquake Engineering (NZSEE Bulletin), 13(1), 22-36, 1980.

[11] A. Javanmardi, Z. Ibrahim, K. Ghaedi, H. Benisi, G. Muhammad, U. Hanif, State-of-the-Art Review of Metallic Dampers: Testing, Development and Implementation. Archives of Computational Methods in Engineering, 2019.

[12] D. De Domenico, N. Impollonia, G. Ricciardi, Seismic retrofitting of confined masonryRC buildings: The case study of the university hall of residence in Messina, Italy. Ingegneria Sismica - International Journal of Earthquake Engineering, 36(1), 54-85, 2019.

[13] A. Wada, Y.H. Huang, M. Iwata, Passive Damping Technology for Buildings in Japan. Progress in Structural Engineering and Materials, 2, 335-350, 2000.

[14] F.C. Ponzo, A Di Cesare, N. Lamarucciola, D. Nigro, Seismic design and testing of post-tensioned timber buildings with dissipative bracing systems. Frontiers in Built Environment, 5(104), 2019. 
[15] T. Polocoser, J. Leimcke, B. Kasal, Report on the seismic performance of threedimensional moment-resisting timber frames with frictional damping in beam-tocolumn connections. Adv. Struct. Eng, 21, 1652-1663, 2018.

[16] W. Pu, C. Liu, F. Dai, Optimum hysteretic damper design for multistory timber structures represented by an improved pinching model. Bull. Earthquake Eng. 16, 62216241, 2018.

[17] F. Mazza, A. Vulcano, Displacement-based design procedure of damped braces for the seismic retrofitting of r.c. framed buildings. Bulletin of Earthquake Engineering, 13(7), 2121-2143, 2015.

[18] F. Braga, F. Buttarazzi, A. Dell'Asta, W. Salvatore, Protezione sismica di edifici in c.a. con controventi dissipativi in acciaio. Dario Flaccovio Editore, 2015.

[19] A. Di Cesare, F.C. Ponzo, Seismic Retrofit of Reinforced Concrete Frame Buildings with Hysteretic Bracing Systems: Design Procedure and Behaviour Factor. Shock and Vibration, 2017.

[20] R.W.K. Chan, F. Albermani, Experimental study of steel slit damper for passive energy dissipation. Engineering Structures, 30(4), 1058-1066, 2008.

[21] Eucentre Lab, Pavia (Italy), website at: https://www.eucentre.it/laboratorytests/?lang=en

[22] CEN - Comité Européen de Normalisation, EN15129 - Antiseismic Devices. Brussels, Belgium, 2009.

[23] E. Gandelli, S. Chernyshov, J. Distl, P. Dubini, F. Weber, A. Taras, Novel adaptive hysteretic damper for enhanced seismic protection of braced buildings, Soil Dynamics and Earthquake Engineering, 141, 2021.

[24] M.J.N. Priestley, G.M. Calvi, M.J. Kowalsky, Displacement-Based Seismic Design of Structures, 2nd edition, Eucentre, 2007.

[25] D. De Domenico, E. Gandelli, V. Quaglini, Adaptive isolation system combining lowfriction sliding pendulum bearing and SMA-based gap dampers. Engineering Structures, 212, 2020.

[26] C.A. Blandon, M.J.N. Priestley, Equivalent viscous damping equations for direct displacement based design. Journal of Earthquake Engineering, 9 (no. spec02), 2005.

[27] CSLLPP - Consiglio Superiore dei Lavori Pubblici. Norme Tecniche per le Costruzioni - NTC2018. Gazzetta Ufficiale della Repubblica Italiana, 2018.

[28] F. McKenna, G.L. Fenves, M.H. Scott, B. Jeremic, Open System for Earthquake Engineering Simulation (OpenSees). Pacific Earthquake Engineering Research Center (PEER), Berkeley, USA, 2000.

[29] I. Iervolino, C. Galasso, E. Cosenza, REXEL: computer aided record selection for codebased seismic structural analysis. Bulletin of Earthquake Engineering, 8, 339-362, 2010. 